\title{
UM CONCEITO REINTERPETADO AO LONGO DO SÉCULO: DO INTELECTUAL INDIVIDUALISTA DE DURKHEIM AO INTELECTUAL COLETIVO DE BOURDIEU
}

\begin{tabular}{c}
\hline CONCEPT REINTERPRETED DURING THE CENTURY: \\
FROM DURKHEIM'S INDIVIDUALIST INTELLECTUAL TO BOURDIEU'S \\
COLLECTIVE INTELLECTUAL \\
UN CONCEPTO REINTERPRETADO A LO LARGO DE UN SIGLO: \\
DEL “INTELECTUAL INDIVIDUALISTA" DE DURKHEIM AL “INTELECTUAL \\
COLECTIVO” DE BOURDIEU
\end{tabular}

Ione Ribeiro Valle

RESUMO: Para contribuir com o debate sobre os intelectuais recorremos a dois sociólogos, distanciados um do outro cerca de um século: Émile Durkheim (1858-1917) e Pierre Bourdieu (1930-2002). O primeiro preconiza a relação entre uma "moral individualista" e o papel do intelectual. Esta reflexão integra o conjunto de suas apostas na coesão social e na moral laica, indispensáveis à promoção do progresso e da ordem nas sociedades em processo crescente de diferenciação. A perspectiva de Bourdieu volta-se à necessidade de "reinventar uma espécie de intelectual coletivo segundo o modelo do que foram os enciclopedistas". Segundo ele, um novo desafio se impõe ao intelectual coletivo: mobilizar a ciência, e a sociologia em particular, na luta contra os usos abusivos da própria ciência e da autoridade científica. As ideias destes pensadores oferecem chaves de leitura que inspiram o desenvolvimento de uma sociologia histórica voltada à educação no pensamento social brasileiro.

PALAVRAS-CHAVE: Intelectual individualista. Intelectual coletivo. Émile Durkheim. Pierre Bourdieu.

ABSTRACT: To contribute to the debate about intellectuals, we turn to two sociologists who have nearly a century between their work: Émile Durkheim (1858-1917) and Pierre Bourdieu (1930-2002). The first recognized the relationship between a "moral individualist" and the role of the intellectual. This reflection is part of his emphasis on social cohesion and secular morality, which are indispensable for the promotion of progress and order in societies in a growing process of differentiation. Bourdieu, meanwhile, focused on the need to "reinvent a type of collective intellectual following the model of the encyclopedistas". For Bourdieu, a new challenge was established for the collective intellectual: to mobilize science, and sociology in particular, in the struggle against the abusive uses of science and scientific authority. The ideas of these thinkers offer guides to reading that inspire the development of a historic sociology focused on education in Brazilian social thinking.

KEYWORDS: Individualist intellectual. Collective intellectual. Émile Durkheim. Pierre Bourdieu.

RESUMEN: Para contribuir al debate sobre los intelectuales recurrimos a dos sociólogos, distantes entre sí por casi un siglo: Émile Durkheim (1858-1917) y Pierre Bourdieu (1930-2002). Durkheim exalta la relación entre una "moral individualista" y el papel del intelectual. Esta reflexión integra el conjunto de sus apuestas por la cohesión social y la moral laica, indispensables para la promoción del progreso y el orden en las sociedades en proceso creciente de diferenciación. En contraste, la perspectiva de Bourdieu impulsa la necesidad de "reinventar una especie de intelectual colectivo siguiendo el modelo de lo que fueron los enciclopedistas". Según él, el intelectual colectivo se enfrenta a un nuevo desafío: movilizar la ciencia, y en particular la sociología, en la lucha contra los usos abusivos de la propia ciencia y de la autoridad científica. Las ideas de estos pensadores proveen claves de lectura que inspiran el desarrollo de una sociología histórica centrada en la educación dentro del pensamiento social brasileño.

PAlabraS Clave: Intelectual individualista. Intelectual colectivo. Émile Durkheim. Pierre Bourdieu.

Submetido em: 31/08/2017 - Aceito em: 22/09/2017 - Publicado em: 12/10/2017.

\begin{tabular}{|l|c|c|c|c|c|}
\hline (C) Rev. Inter. Educ. Sup. & Campinas, SP & v.4 & n.1 & p.95-111 & jan./abr. 2018 \\
\hline
\end{tabular}


Que o perigo comum nos sirva pelo menos para sacudir nosso entorpecimento, e para nos fazer retomar o gosto pela ação!

Émile Durkheim

(1858-1917)

Chego a pensar que o único apoio que se pode encontrar no mundo social, quando se tenta dizer um pouco da verdade desse mundo, estaria na solidariedade entre os eruditos.

Pierre Bourdieu

(1930-2002)

Refletir sobre os intelectuais, sobre o lugar que ocupam nas sociedades contemporâneas supõe reconhecer que a figura do intelectual é mais uma das belas produções dos tempos modernos. Ainda que empregado de forma recorrente a menos de um século, o termo já fez história atraindo pensadores de diferentes áreas do conhecimento e em diferentes momentos históricos, interessados nos sentidos e possibilidades das noções de intelligentsia e intelectuais para a história cultural (VIEIRA, 2008²), e instigando a construção de modelos de intervenção política, orientados segundo seus capitais simbólicos e graus de especialização $\left(\right.$ SAPIRO, 2012 ${ }^{3}$ ). Nesses modelos, a concepção de intelectual transita entre os ideais do mundo científico e literário e as apostas do mundo político.

Apesar das controvérsias eruditas, não suficientemente conhecidas e elucidadas, esse termo se tornou, como lembra Charle (1990, p. 7), “indispensável ao discurso político, ideológico, sociológico, histórico, psicológico, mesmo sendo banalizado e estando desgastado pelo uso abusivo de sentidos contraditórios". Não se pode deixar de sublinhar que uma abordagem pautada numa sociologia histórica dos intelectuais somente tem sentido quando explora concomitantemente dois movimentos: a posição do conceito no interior do espaço global do campo do poder do seu tempo e as aproximações e distanciamentos em relação ao contexto atual.

A discussão sobre os intelectuais permanece, como se pode ver, não apenas atravessada por paradoxos mas fundamental aos embates que envolvem o mundo acadêmico e político. Certamente, não se trata de uma discussão encerrada - uma vez que não percebemos, como já foi aventado, o fim dos intelectuais -, pois a figura do intelectual, seja como ator, agente ou

\footnotetext{
${ }^{2}$ Carlos Eduardo Vieira explora, em seu artigo intitulado "Intelligentsia e intelectuais: sentidos, conceitos e possibilidades para a história cultural", as concepções de intelectual apresentadas por Karl Mannheim, que o vê como mediador de conflitos sociais, por Antonio Gramsci, que o considera como dirigente e organizador da cultura, e por Pierre Bourdieu, que o coloca como agente privilegiado na produção de capital simbólico.

${ }^{3}$ Diferentemente de Vieira que centra sua reflexão em três pensadores, Gisèle Sapiro interessa-se, em seu texto intitulado "Modelos de intervenção política dos intelectuais: o caso francês", pelos fatores que interferem nas formas de tomada de posição do ponto de vista discursivo, mais do que o conteúdo dessas posições. Além disso, a autora constrói ideais-típicos: o intelectual crítico universalista, o guardião da ordem moralizador, o grupo intelectual contestador e a 'vanguarda', o intelectual de instituição ou de organização política, o especialista consultado pelos dirigentes ou o 'expert', o intelectual crítico especializado ou o 'intelectual específico' e o grupo contestador especializado ou o 'intelectual coletivo'.
}

\begin{tabular}{l|l|r} 
(C) Rev. Inter. Educ. Sup. & Campinas, SP & v.4
\end{tabular}

n.1

p.95-111

jan./abr. 2018 
intérprete, sempre aparece vinculada às transformações sociais e políticas, gerais ou específicas, que atingem, e cada vez com mais intensidade e rapidez, o Estado moderno (democrático) e suas instituições de produção artística, literária e científica.

Assim, para contribuir com o debate priorizado neste momento, cujo objetivo é dar visibilidade aos intelectuais em diferentes projetos educacionais, nos propusemos a revisitar dois pensadores que colocam o intelectual no centro dos desafios políticos das sociedades, idealizadas ou observáveis, do seu tempo: Émile Durkheim (1858-1917) e Pierre Bourdieu (1930-2002) ${ }^{4}$. A escolha destes pensadores levou em consideração ao menos três aspectos: seus pertencimentos à tradição sociológica francesa que muito se interessou pela relação entre o intelectual, o saber e a educação, o fato de terem investido no diálogo entre sociologia e história, situando-se portanto na base de uma racionalidade crítica, mas sobretudo a força de suas presenças na composição da intelectualidade brasileira, em geral, e do campo educacional brasileiro, em particular.

Portanto, não importam as estratégias escolhidas face às novas situações que cercam o campo intelectual, esse termo se mostra pertinente, passando a ser, para aqueles que produzem apenas para os seus pares, a marca de um novo elitismo, ou, para aqueles que jogam o jogo das carreiras clássicas e profissionais, uma reivindicação de justiça representada pela perspectiva da crítica global. Ou, ainda, pode apresentar-se como "um estado social capaz de engendrar impasses sociais para os que denunciam o proletariado intelectual, utilizando estratégias de sobrevivência externas" (CHARLE, 1990, p. 64).

\section{O “INDIVIDUALISMO MORAL” COMO “IDEAL DA DIGNIDADE HUMANA"}

A obra de Émile Durkheim, em sua integralidade, dispensa comentários assim como o próprio autor que, juntamente com Karl Marx (1818-1883) e Max Weber (1864-1918), compõe a trilogia dos pais fundadores da sociologia e, no seu caso em particular, da sociologia da educação. $\mathrm{O}$ interesse pela pesquisa de diferentes temas que marcou os primeiros anos do empreendimento sociológico de Durkheim, materializado em algumas obras de grande notoriedade, como a Divisão do trabalho social (1893), As regras do método sociológico (1895) e $O$ suicídio (1897), se sustentou na sua principal preocupação: a coesão e a solidariedade sociais. Isso significa que todo o seu pensamento apresenta "um caráter propositivo e cientificamente engajado" e se mantém "como elemento que sustenta todas as posições" (CONSOLIM, OLIVEIRA; WEISS, 2016, p. 18), e que explica o conjunto das questões por ele tratadas.

\footnotetext{
${ }^{4}$ Uma primeira reflexão sobre esta temática foi apresentada numa mesa no IX Congresso Brasileiro de História da Educação, realizado entre 15 e 18 de agosto de 2017, em João Pessoa, Paraíba.
} 
A questão da moral, como se sabe, é um dos pilares do edifício teórico deste pensador, situando-se na base das reflexões voltadas à socialização das novas gerações e à promoção do espírito de disciplina e de autonomia. Ou seja, é sobretudo na abordagem sobre a função social da educação (escolar) que a questão da moral aparece com mais evidência. Ele dedica o curso de ciência da educação, que compreende 20 lições, ministrado pela primeira vez na Sorbonne no ano letivo de 1902-1903, à relação entre educação e moral, iniciando pela formulação de uma concepção de moral laica, seguida de reflexões relativas aos elementos da moralidade e às formas de construção na criança desses elementos ${ }^{5}$.

Mas essas lições não foram as únicas a expressar seu interesse pelo que definiu como "caráter essencial da moral". Podemos citar, por exemplo, a conferência proferida na Escola Normal de Auteuil, intitulada $O$ ensino da moral na escola primária. Esta conferência, que se estima ter ocorrido na primeira década do século XX, permaneceu inédita cerca de 80 anos, como relata Raquel Weiss ao apresentar sua tradução para o português, datada de 2007. Ela foi publicada somente em 1992 pela Revue Française de Sociologie, após ter sido encontrada nos arquivos do Instituto Universitário de Formação de Mestres (IUFM). O que se destaca neste texto é a importância atribuída à moral laica nas sociedades em processo crescente de diferenciação social, justificando assim sua inclusão no ensino primário:

\footnotetext{
Já não se trata de uma educação puramente livresca. O ensino da moral consiste em fazer com que se enxergue uma realidade, em fazer com que essa realidade possa ser tocada com as mãos. Ensinar as ciências é ensinar algo real. Ensinar a moral é demonstrar como a moral se relaciona com algo real (DURKHEIM, 2007, p. 73).
}

A preocupação em assegurar o ensino de uma moral laica às novas gerações é no entanto precedida temporalmente por um apelo ao engajamento (militante) dos intelectuais, o que nos leva a inferir que toda sua produção científica tem um caráter não apenas propositivo, o que sempre foi evidente quando se trata da educação, mas também marcado por um tipo de engajamento político moralizador. Ora, isso nada tem de axiomático, ao contrário, supunha romper com o círculo vicioso das definições abstratas ou meramente normativas que, de certa forma, caracterizavam a ação dos pensadores a época. Em outras palavras, e nos termos elaborados por Charle (1990, p. 29) na sua obra dedicada ao nascimento dos intelectuais (1880-1900), "desde o evento da república os sábios foram associados à obra patriótica e revolucionária da defesa nacional, permanecendo como especialistas ou técnicos e não como um tipo social que podia interessar a toda humanidade"

\footnotetext{
${ }^{5}$ A organização de uma obra póstuma reunindo 18 das lições que compuseram esse curso foi realizada por Paul Fauconnet (1874-1938), um de seus colaboradores na revista L'Année sociologique, tendo sido publicada pela Editora Félix Alcan em 1925, com o título L'éducation morale. Esta obra de Durkheim foi traduzida para o português com o título Educação moral e publicada pela Editora Vozes em 2008.

${ }^{6}$ Charle também lembra que "a partir dos anos 1850-1860 a ciência se coloca como substituta da religião. Esse fenômeno bem conhecido da história das ideias oculta outro menos analisado pelo seu papel na evolução das representações sociais, e que constitui uma ligação central na gênese do 'intelectual', o surgimento do sábio como emblema simbólico alternativo às representações anteriores” (1990, p. 28).

\begin{tabular}{|l|c|c|c|c|c|}
\hline (C) Rev. Inter. Educ. Sup. & Campinas, SP & v.4 & n.1 & p.95-111 & jan./abr. 2018 \\
\hline
\end{tabular}
}


(1822-1895), nos escritos em que defende a promoção da pesquisa científica, sempre corroborou com este argumento.

Evidentemente, a inflexão no modo de pensar e proceder de Durkheim - de sociólogo a intelectual, de intelectual a sociólogo e pedagogo -, e que o levou a passar de uma postura pessoal a uma identidade coletiva, não apresenta nenhum pioneirismo. Segundo Pinto (2016, p. 73),

Desde o final dos anos 1890, a figura do intelectual tinha se constituído em torno do grupo dos universitários inovadores e críticos do tradicionalismo, ligados às reformas políticas e pedagógicas e a valores que refletiam as exigências da divisão do trabalho intelectual.

Assim, o que há de incomum nessa nova investidura está no apelo à tomada de posição política, seja pela adesão ou pela contestação, em episódios que despertam o interesse da sociedade em geral e da imprensa em particular, e que suscitam polêmica no interior do corpo de sábios, literatos e universitários.

Vale lembrar contudo que o termo intelectual enfrentava naquele momento uma indefinição semântica considerável quanto à sua identidade coletiva de novo grupo social. Como mostra Charle (1999, p 55), os intelectuais foram definidos "por outros intelectuais que os rejeitavam em função de concepções, mais tradicionais, como a do clérigo, ou mais revolucionárias, como a do ideólogo partidário". Isso significa que a imagem que caracterizava esse novo grupo foi atribuída pelos que não pertenciam a ele ou que se posicionavam contra ele. Para estes, a identificação como intelectual tinha um sentido fortemente pejorativo. No entanto, desde que o termo intelectual se difundiu passando a abranger o corpo de sábios e não apenas os dreyfusards (referindo-se aos que se mobilizaram em favor do Caso Dreyfus ${ }^{7}$ ), os antidreyfusards precisaram dedicar-se a um novo tipo de luta simbólica, visando garantir o que haviam edificado até então (CHARLE, 1990).

Esse movimento, que assumiu uma dimensão fortemente política, provocou uma redefinição da função social do intelectual, além de colocá-lo numa condição fortemente ambígua: ainda que pertença à elite, ele pode se opor a ela ou à sua verdadeira realização; o intelectual pode, portanto, comprometer-se com expectativas políticas e sociais que podem ser contrárias aos interesses dessa mesma elite. Segundo Charle (1990), os intelectuais passam a se manifestar

\footnotetext{
${ }^{7}$ O Caso Dreyfus tem sido objeto de incontáveis estudos, produzidos a partir de diferentes abordagens teóricas e áreas do conhecimento. Trata-se de um episódio de espionage, iniciado em 1894, que incriminou o capitão Alfred Dreyfus, acusado de vender informações secretas aos alemães. O exército francês armou um processo que condenou o capitão à prisão perpétua, apesar das comprovações de sua inocência. Ao ser descoberta essa trama, a sociedade intelectual francesa se mobilizou, as posições se dividiram, manifestos foram assinados, cartas foram publicadas, como a de Émile Zola ao Presidente da República, intitulada J'accuse...!, que apareceu no jornal parisiense L'Aurore em 1898, e foi uma espécie de estopim do movimento de contestação. Sobre o Caso Dreyfus, ver por exemplo Vieira (2008), Sapiro (2012), Miller (2016), Consolim, Oliveira; Weiss (2016), Charle (1990).
}

\begin{tabular}{l|l|l|l|l|l}
\hline () Rev. Inter. Educ. Sup. & Campinas, SP & v.4 & n.1 & p.95-111 & jan./abr. 2018
\end{tabular}


pelo direito ao escândalo, pelo direito de se unir para dar mais força aos protestos, pelo direito de reivindicar um poder simbólico decorrente da acumulação de títulos (de nobreza escolar). Essas manifestações tiveram como consequência a instauração de uma nova legitimidade cultural aliando "o rigor do sábio, a luta pela liberdade de pensamento e a abertura aos problemas contemporâneos" (CHARLE, 1990, p. 31).

Ao tomarmos como principal referência para esta reflexão o texto $O$ individualismo $e$ os intelectuais de Durkheim, publicado em 1898, que torna pública sua tomada de posição no Caso Dreyfus, e que consiste numa resposta ao artigo de Ferdinand Brunetière ${ }^{8}$, publicado poucos meses antes, nos colocamos dentre os que consideram este episódio como um marco na implementação dessa nova função social. Ou seja, ao se posicionar em favor dos que defendiam o capitão Dreyfuss, ao compartilhar com os que colocam sua razão acima da autoridade por entender que "o direito do indivíduo lhes parece imprescindível" (MARTUCCELLI; DE SINGLY, 2012, p. 14), Durkheim integra o grupo dos que se deslocam para o centro da cena política, e portanto pública, e que lançam por terra as muralhas que por muito tempo encerraram os pensadores numa espécie de torre de marfim. Eles inauguram, assinala Charle (1990), novos modos de expressão coletiva, como se estivessem reeditando repetidamente o Caso Dreyfus, de modo que, o que realmente importa a Durkheim (2016) é o estado de espírito dos intelectuais, as ideias que defendem e não o detalhe dos seus argumentos.

Mas o principal interesse por este artigo neste momento está relacionado à noção de individualismo moral $^{9}$ que fundamenta todos os argumentos do autor. Segundo Consolim, Oliveira; Weiss (2016, p. 18),

Durkheim apresenta nova fundamentação para o ideal do individualismo moral e, ao mesmo tempo, justifica a necessidade de sua defesa a partir das próprias condições de existência daquela sociedade, fazendo com que tanto sua origem quanto sua finalidade lhe sejam imanentes.

A defesa contundente de um tipo de individualismo que, segundo Jones (2016, p. 87), não é incompatível com a ideia de razão, uma vez que "o racionalismo é a 'expressão intelectual do individualismo"”, explicita seu ponto de vista, certamente polêmico, sobre a relação entre

\footnotetext{
${ }^{8}$ Crítico literário, vinculado à Revue des deux mondes, Brunetière, visto por Sapiro (2012) como um dos guardiões da ordem moralizadora, integra o grupo dos intelectuais que se posicionaram contrários ao capitão Dreyfus. Ele publica em 1898 um artigo intitulado "Após o processo", no qual acusa os intelectuais dreyfusards de perversão ao intervirem num terreno que não era de sua competência. A respeito do artigo e da polêmica gerada, ver por exemplo o artigo do próprio Brunetière (2016), mas também alguns dos seus comentadores, a saber: Consolim, Oliveira; Weiss (2016), Consolim (2016), Charle (1990).

${ }^{9}$ Segundo Martuccelli; De Singly (2012, p. 14), Durkheim sustenta um certo individualismo, ao sublinhar que ele se tornou "a base para o nosso catecismo moral". E ele não utilize esse termo por acaso, afirmam os autores, pois considera o individualismo como uma religião - a religião dos tempos modernos -, na qual o homem é ao mesmo tempo fiel e Deus, tornando-se um princípio universal por meio do qual se pode organizar a sociedade.

\begin{tabular}{l|l|l|l|l|l|}
\hline (C) Rev. Inter. Educ. Sup. & Campinas, SP & v.4 & n.1 & p.95-111 & jan./abr. 2018 \\
\hline
\end{tabular}
}


indivíduo e sociedade: "essa ideia da pessoa humana, com as diferentes nuances em função da diversidade dos temperamentos nacionais, é [...] a única que se mantém imutável e impessoal, para além da corrente cambiante das opiniões particulares" (DURKHEIM, 2016, p. 55).

Um dos problemas que afeta a noção de individualismo, segundo Durkheim (2016, p. 41), diz respeito ao fato da mesma ser confundida com "o utilitarismo estreito e com o egoísmo utilitário de Spencer ${ }^{10}$ e dos economistas". Além disso, a noção de individualismo por ele formulada não tem nada a ver com anarquia, ao contrário, refere-se à construção de um sistema único de crenças que visa garantir a unidade moral dos estados nacionais, em formação a época.

É importante assinalar que Durkheim distingue dois individualismos em permanente tensão: um negativo, que se exprime pelo termo egoísmo, outro positivo (ou abstrato, nos termos de De Singly (2005), porque independe da individualidade de cada um), que respeita cada um como representante da humanidade e da razão. É esse caráter positivo que define o individualismo moral que "não consiste em preferir o indivíduo ao grupo, mas em propor como fundamento da sociedade moderna uma forma de sagrado que, como tal, esteja dotada de força coletiva" (PINTO, 2016, p. 73). Enfim, enquanto o individualismo moral torna possível a estabilidade do "todo" social, da ligação social, o individualismo egoísta - objeto da apologia dos economistas da época - contribui para desagregar a ligação social, possibilitando o que Durkheim chamou de "anomia" que nada mais é do que a desagregação das referências morais na sociedade (CORCUFF, 2005, p. 4).

Como se pode ver, a moral (laica), que ele elege nos anos subsequentes como uma das principais dimensões da função educativa, assume uma importância considerável nos enunciados que argumentam em favor do estreitamento das relações entre o individualismo e os intelectuais. Ele chama a atenção para a necessidade de persuasão, pois

quando se exige de certos homens que se agrupem em torno de um sentimento que não é o seu, para convencê-los, não basta lembrá-los desse lugar comum da retórica banal, segundo o qual a sociedade não é possível sem sacrifícios mútuos e sem algum espírito de subordinação, mas é preciso também justificar nesse caso específico a docilidade que se lhes pede, demonstrando sua incompetência (DURKHEIM, 2016, p. 51).

Nesse quadro de raciocínio, segundo Pinto (2016, p. 74), o intelectual

não tem 'o monopólio da inteligência', mas, devido aos 'hábitos profissionais' de sua especialidade, possui algo que está mais adiante: uma disposição ao universal, ao uso da 'inteligência' como um fim em si, e não como um instrumento a serviço de um fim social predeterminado.

\footnotetext{
${ }^{10}$ Ao se referir criticamente a Spencer e ao considerar decadente o seu modo de pensar, Durkheim (2016, p. 41) assinala que sua filosofia prática "é de tal miséria moral que quase não tem mais partidários".

\begin{tabular}{|l|c|c|c|c|c|}
\hline (C) Rev. Inter. Educ. Sup. & Campinas, SP & v.4 & n.1 & p.95-111 & jan./abr. 2018 \\
\hline
\end{tabular}
}


Ou, em outras palavras, é essencial "compreender como o moderno papel público do intelectual transcende a sala de aula, assim como avança para além da pesquisa acadêmica, embora esteja vinculado a esta" (MILLER, 2016, p. 113).

Segundo Durkheim o individualismo, como doutrina, fez-se realidade, transformando-se consequentemente em impulso necessário. Ora, suspender esse impulso supõe impedir o processo de diferenciação crescente entre os homens, significa

nivelar suas personalidades, reconduzi-los ao velho conformismo de outrora, conter, por conseguinte, a tendência das sociedades de se tornarem cada vez mais extensas e mais centralizadas, e criar um obstáculo ao progresso incessante da divisão do trabalho (2016, p. 55).

É num contexto de ampliação da solidariedade orgânica, própria das sociedades modernas, em que as relações se tornam mais complexas e mais efervescentes, que a moralidade ganha importância e, como mostra Miller (2016, p. 118), se inscreve no conjunto das preocupações de Durkheim

com os perigos da perda de ilusões e com a degenerescência do entusiasmo em desencantamento [...], em que manifestava sua preocupação de que as elevadas esperanças de uma onda de 'entusiasmo' fossem logo seguidas por um amargo desencantamento.

Enfim, é nesse contexto que a luta política dos intelectuais assume uma dimensão ideológica e passa a responder a conjunturas precisas, submetidas a mudanças abruptas. Charle (1990) mostra que desde o final do século XIX os intelectuais não se deixam assimilar por um determinado grupo social, imaginam-se distintos das demais elites, chegam a pretender ser a única e verdadeira elite. Esse processo ganha força graças às sucessivas reformas universitárias, as quais revigoram as profissões intelectuais em relação às profissões liberais clássicas, provocando uma forte diferenciação interna ${ }^{11}$. Ora, essa diferenciação está na base da noção de campo intelectual, elaborada por Pierre Bourdieu, que vislumbra a reinvenção de uma espécie de intelectual coletivo.

\footnotetext{
${ }^{11}$ Os intelectuais acabam, com muita frequência, praticando distinções internas: "verdadeiros intelectuais contra falsos intelectuais, semi-intelectuais contra grandes intelectuais, escritores contra universitários, velhos contra jovens, vanguarda contra autores de sucesso ou acadêmicos, jornalistas contra poetas, esquerda contra direita" (CHARLE, 1999, p. 10).

(C) Rev. Inter. Educ. Sup. Campinas, SP v. 4 n.1 p.95-111 jan./abr. 2018
} 


\section{UM INTELECTUAL COLETIVO SEGUNDO 0 Q QUE FORAM OS ENCICLOPEDISTAS}

Referir-se a Pierre Bourdieu ou à sua obra nada tem de excepcional, haja vista a repercussão do seu pensamento junto ao mundo intelectual, graças à diversidade de textos traduzidos ou de trabalhos que mergulharam sobre seu viés analítico ${ }^{12}$. O interesse pela questão dos intelectuais, em particular, atravessa o conjunto de sua obra e se orienta a partir de uma imbricação cada vez mais profunda entre os campos literário e científico e o campo político. Poderíamos mencionar vários autores, inclusive brasileiros, que tomaram como objeto sua abordagem sobre os intelectuais. Nesse caso, qual seria a motivação para abordar este autor e este tema neste momento?

Dois motivos orientam nosso intento. Primeiramente, a constatação de que a "invenção do intelectual", nos termos apresentados por Bourdieu tendo como referência a manifestação de Émile Zola no Caso Dreyfus - J'accuse! $!^{13}$ [Eu acuso!] - (apud Durkheim, 2016), promove uma profunda inflexão no interior do corpo de sábios do final do século XIX, que consiste na emergência de uma verdadeira missão profética, ao mesmo tempo intelectual e política ${ }^{14}$. Embora Durkheim também tenha sido mobilizado por este mesmo episódio, a perspectiva adotada por Bourdieu se distancia do individualismo moral durkheimiano, porque incorpora a noção de campo dando grande importância à sua autonomia e diferenciação interna: "a intervenção do intelectual, que se completa com Zola, não supõe somente a autonomização preliminar do campo intelectual. Ela é a realização de outro processo, paralelo, de diferenciação, que leva à constituição de um corpo de profissionais da política" (BOURDIEU, 1992, p. 187).

Em segundo lugar, o fato de considerarmos a ideia de intelectual coletivo como novidade no âmbito da produção e do engajamento político desses profissionais; ideia esta que, do nosso ponto de vista, ainda não foi suficientemente explorada. Ao compor modelos, tendo como referência a intervenção dos intelectuais na ordem política, Sapiro (2012) mostra que há algo novo nesta forma de atuar que se distancia - ou se diferencia - das formas até então praticadas. Nesta mesma direção, podemos situar a análise desenvolvida por Vieira (2008),

\footnotetext{
12 Destacamos aqui algumas produções recentes sobre Pierre Bourdieu, especificamente em relação à questão educacional: Valle (2007, 2008, 2011, 2013, 2014), Valle, Catani, Da Silva; Santos (2015), Valle, Mezzaroba, Cândido, Grimm; Rohling (2015).

${ }^{13}$ Para Bourdieu (1992, p. 186), o artigo 'Eu acuso' de Zola “é a consolidação do processo de emancipação que ocorreu progressivamente no campo de produção cultural: como ruptura profética com a ordem estabelecida, ele reafirma, contra todas as razões de Estado, a irredutibilidade dos valores de verdade e de justiça e, assim, a independência dos guardiões desses valores em relação às normas da política (as do patriotismo por exemplo) e às imposições da verdade econômica".

${ }^{14}$ Segundo Bourdieu (1992, p. 186), o Caso Dreyfus traz para o campo político um problema construído segundo os princípios de divisão característicos do campo intelectual, impondo a todo o universo social as leis não escritas desse mundo particular que tem como particularidade invocar o universal.

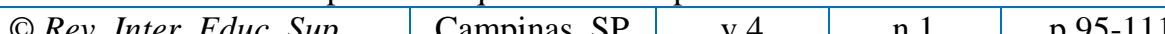


que destaca no pensamento de Bourdieu o entrelaçamento entre dominação econômica, política e cultural, entre estruturas mentais/simbólicas e estruturas sociais, o que consequentemente o distingue de Mannheim e Gramsci ${ }^{15}$.

Assim, para explicitar o que Bourdieu entende por intelectual coletivo faz-se necessário retomar, ainda que brevemente, a centralidade das noções de campo e de campo científico na sua obra. Uma das primeiras formulações relativas a essa questão aparece já em 1976, num artigo em que o autor analisa a luta pelo monopólio da competência científica e as implicações da acumulação de capital científico ${ }^{16}$. Desde então, a questão do intelectual se torna recorrente nas suas reflexões; ele passa a ser considerado como alguém que intermedeia as relações entre a educação e as elites e participa, mais ou menos intensamente, mais ou menos conscientemente, da dominação e da reprodução social.

Nesse sentido, o campo científico coloca-se na condição ou, mais precisamente, na posição de campo do poder $^{17}$, embora reafirme a pluralidade dos pontos de vista, inscrita na própria existência desse campo. Ao se organizar em dois níveis hierárquicos - "a hierarquia do poder econômico e político e a hierarquia da autoridade e do prestígio intelectual” (BOURDIEU, 1989, p. 75) -, o campo científico estabelece níveis diversos de autonomia. Estes reafirmam a complexidade das vias da autonomia, ou até mesmo sua impenetrabilidade, assim como ocorre com as vias da dominação. Ora, não se pode deixar de considerar que "num universo científico ou universitário no sentido amplo, o poder sempre [é] culturalmente sublimado: aquele que defende uma autoridade acadêmica defende uma definição de cultura, uma maneira de fazer ciência, uma metodologia" (BOURDIEU, 1993, p. 55).

Merece destaque neste quadro de discussão a obra Homo academicus ${ }^{18}$, publicada em 1984, e que tem como pano de fundo as tomadas de posição dos universitários frente ao maio de 1968. Nela Bourdieu mostra a complexidade que atinge o tecido acadêmico e científico

\footnotetext{
15 Segundo Vieira (2008, p. 79), "Bourdieu - descrente no partido político, de maneira geral, e no Partido Comunista Francês, de maneira particular - distanciou-se de Gramsci relativamente aos meios de subversão do poder estabelecido. Contudo, não cancelou essa possibilidade, uma vez que a sua obra e, sobretudo, a sua intensa militância política evidenciam essas crenças na capacidade de insubordinação dos sujeitos e no poder de crítica do conhecimento".

${ }^{16}$ Este texto está disponível em português: Bourdieu (1983, p. 122-155).

${ }^{17}$ Segundo Bourdieu (2007, p. 296), "As diferentes espécies de capital - cuja posse define o pertencimento à classe e cuja distribuição determina a posição nas relações de força constitutivas do campo do poder e, por conseguinte, das estratégias susceptíveis de serem adotadas nessas lutas (em outras épocas, 'nascimento', 'fortuna' e 'talentos'; atualmente, capital econômico e capital escolar) - são, ao mesmo tempo, instrumentos de poder e pretextos de luta pelo poder, desigualmente poderosos de fato e desigualmente reconhecidos como princípios de autoridade ou sinais de distinção legítimos segundo os momentos e, evidentemente, segundo as frações".

${ }^{18}$ Segundo Autor (2011, p. 18), "Em Homo academicus, Bourdieu desenvolve uma análise particularmente fina e penetrante do meio universitário, que parece dever muito ao conhecimento íntimo e familiar que ele tem desse espaço social, explicitando, inclusive nas modificações morfológicas que passaram a influenciá-lo, principalmente a partir de maio de 1968, a dialética da conservação e do reconhecimento".
}

\begin{tabular}{l|l|l|l|l|l}
\hline (C) Rev. Inter. Educ. Sup. & Campinas, SP & v.4 & n.1 & p.95-111 & jan./abr. 2018 \\
\hline
\end{tabular}


sobretudo nos momentos políticos mais críticos; momentos marcados por questionamentos generalizados sobre a verdade, assumindo portanto um caráter puramente político, sobre a justiça, quando se põem em xeque muitas das regras do direito; momentos enfim em que a moralidade como um todo é posta sob suspeição.

Esses momentos críticos - ou de crise - tendem a provocar conversões e a funcionar

\begin{abstract}
como uma espécie de ritual coletivo de ruptura com as rotinas e apegos ordinários destinado a levar à metanoia, à conversão espiritual, a crise suscita inúmeras conversões simultâneas, que se reforçam e se sustentam mutuamente; ela transforma o olhar que os agentes têm habitualmente sobre a simbólica das relações sociais, e principalmente das hierarquias, fazendo ressurgir a dimensão política, altamente reprimida, das práticas simbólicas mais ordinárias (BOURDIEU, 2011, p. 247).
\end{abstract}

A importância desses momentos na obra de Bourdieu é indiscutível. Preocupado em compreender a "gênese" dos fenômenos, assim como os fatores que desencadeiam certas rupturas - rupturas na continuidade ou continuidades na ruptura -, ele recorre à noção de "jogo intelectual", associando-o a ideia de illusio $^{19}$. Bourdieu apreende esse jogo como um dos dispositivos que possibilitam a mobilização das mais diversas paixões, políticas e ideológicas, no interior do campo intelectual, lembrando que "existem no campo científico poderes sociais que podem servir de base a atos tirânicos" (1993, p. 55). Para ele,

\begin{abstract}
O campo científico é como um jogo, que é inventado pouco a pouco, sem inventor, através de uma série de instituições, os congressos eruditos, os anais de congressos, as publicações, os gatekeepers que controlam o acesso à publicação, toda uma tradição científica, regras, protocolos de verificação, bancas. Tudo isso faz com que a violência pura seja sublimada, com que se deva curvar-se às regras ou, melhor, às regularidades que estão inscritas nos mecanismos. E não a regras morais. Frequentemente se diz: o erudito deve contar com sua consciência, sua deontologia, ou, como se diz hoje, sua "ética" (BOURDIEU, 1993, p. 55).
\end{abstract}

Note-se que nosso autor desenvolve uma dinâmica de análise que permite compreender as disputas entre projetos políticos e ideológicos engendradas no interior do microcosmo científico. Ou seja, é possível apreender um ponto de vista a partir da posição ocupada no campo intelectual, uma vez que "a distância aristocrática dos intelectuais conservadores oriundos da grande burguesia, por ela reconhecidos e dotados de uma forma de consagração social, se opõe à marginalidade dos 'intelectuais proletaróides', originários da pequena burguesia" (BOURDIEU, 1992, p. 271-272). Assim, a inclinação a um certo otimismo universal pode obnubilar a percepção objetiva dos fatos, pois "muitos discursos justificativos têm como único princípio a universalização, não apenas de uma maneira de ser, mas do

\footnotetext{
${ }^{19}$ Este termo integra a abordagem de Bourdieu sobre o jogo, no sentido de "estar no jogo", "estar preso ao jogo", "ser pego pelo jogo", o que leva a investir no jogo. Ou seja, illusio supõe entrar no jogo, aderir ao jogo, estar convencido de que vale a pena jogar. Sobre esta questão, ver Bourdieu (1992, p. 453-458) e Bourdieu (2015, p. 314-315).

\begin{tabular}{|l|l|l|l|l|l|}
\hline (C) Rev. Inter. Educ. Sup. & Campinas, SP & v.4 & n.1 & p.95-111 & jan./abr. 2018 \\
\hline
\end{tabular}
}


princípio a partir do qual essa maneira de ser se constitui como a maneira excelente de ser" (BOURDIEU, 2015, p. 140).

Inscrito portanto num campo do poder, onde se aprende desde muito cedo a jogar com o capital simbólico e político, mas também a mobilizar outros capitais (herdados ou acumulados na dinâmica da meritocracia escolar), o intelectual "é alguém que, partindo de uma autoridade específica adquirida nas lutas internas ao campo intelectual, artístico, literário, segundo os valores inerentes a esses universos relativamente autônomos, intervém no campo político" (BOURDIEU, 2012, p. 350). E ele somente o faz porque está legitimado por essa autoridade (reconhecida), por virtudes morais, por uma determinada competência, por méritos pessoais.

Mas como definir o "intelectual coletivo" que aparece como o modelo mais recente de intervenção dos intelectuais? Ao menos dois aspectos parecem explicitar esta nova maneira de se posicionar e de intervir nas questões políticas: a crescente desvinculação da promessa de ascensão às elites da herança social, econômica e cultural, em razão dos avanços da meritocracia escolar ${ }^{20}$, e a consequente evolução morfológica das profissões intelectuais, resultante da distensão da relação, antes estreita e fortemente orgânica, entre riqueza, saber e exercício do poder. Ora, essa distensão apresenta implicações, diretas ou indiretas, sobre a reprodução das bases sociais da elite, além de promover a ampliação da fratura no interior das elites dominantes, cada vez mais numerosas e por isso em processo cresceste de declínio social e simbólico.

Ao formular este modelo de intervenção política, intitulado: o grupo contestador especializado ou o 'intelectual coletivo', Sapiro (2012, p. 48) observa que o mesmo se pauta inteiramente na especialização e na divisão do trabalho de expert, calcada numa

\begin{abstract}
forma de ação coletiva fundada no acúmulo das competências em uma área de conhecimento determinada. Em oposição ao individualismo característico do mundo das letras, onde reina o paradigma da singularidade, este modelo remete ao modo de funcionamento do campo científico, fundado no trabalho em equipe e no acúmulo de conhecimentos, inaugurando um novo modo de intervenção coletiva baseado em trabalhos científicos.
\end{abstract}

Após mencionar diversas experiências intelectuais levadas a efeito a partir desta prática, particularmente após os anos 1970, Sapiro (2012) toma como referência a experiência do coletivo Raisons d'Agir, fundado por Bourdieu e seus colaboradores em 1996, cujo objetivo principal era continuar combatendo o neoliberalismo. Ora, esse novo modo de atuação do

\footnotetext{
${ }^{20}$ Ao refletir sobre "a emergência de uma estrutura dualista" no interior do mundo intelectual, Bourdieu (1992, p. 183) dá grande destaque ao crescimento da população escolarizada em todos os níveis de ensino. Este fator estaria no princípio de dois processos paralelos: "o aumento no número dos produtores que conseguem viver de sua pluma ou tirar sua subsistência dos pequenos métiers oferecidos pelas empresas culturais [e] a expansão do mercado dos leitores potenciais".

\begin{tabular}{|l|c|c|c|c|c|}
\hline (C) Rev. Inter. Educ. Sup. & Campinas, SP & v.4 & n.1 & p.95-111 & jan./abr. 2018 \\
\hline
\end{tabular}
}


intelectual, fortemente ancorado na profissionalização da produção científica e por ela legitimado, aparece como o único capaz de

evitar que a ciência continue avançando segundo a lógica de mecanismos mais poderosos do que os indivíduos [...], seria preciso reinventar uma espécie de intelectual coletivo segundo o modelo do que foram os enciclopedistas. Mas cada pesquisador está preso aos limites de sua ciência, de seus problemas de ponta: a ciência avança muito rapidamente e para fazer as pesquisas experimentais, para se manter ao par, ler as revistas, já é difícil. Donde viria a energia social capaz de obrigar todas as pessoas a desviarem uma pequena parte da sua energia, ou seja, do seu tempo, desse elemento raro dentre os demais, para refletir coletivamente sobre o que se faz? (BOURDIEU, 1993, p. 56).

\section{POR UM CORPORATIVISMO DO UNIVERSAL}

Tendo como referência as reflexões, mas também as tomadas de posição política desses dois sociólogos (Durkheim e Bourdieu), e a título de conclusão, observamos que por ter ocorrido, inclusive no caso brasileiro, uma ampliação considerável do mundo intelectual, novos desafios se impõem ao campo científico. Não parece haver mais espaço nem para o sábio ou o literato desinteressado pelas coisas do espírito, nem para o intelectual individualista situado num ambiente de profunda exaltação intelectual, que favorece tanto os grupos heréticos quanto os guardiões da ordem econômica e simbólica, tampouco para o "intelectual total", segundo o formato inventado e encarnado por Jean-Paul Sartre ${ }^{21}$ (1905-1980).

Bourdieu (1992, p. 465), reconhece que estamos inseridos num jogo em que tudo parece já ter sido jogado, aqui e acolá: a rejeição ao político, o retorno ao religioso, a resistência à ação de um poder político hostil às coisas intelectuais, a revolta contra as mídias, o abandono excessivo das utopias revolucionárias. O desafio, para Bourdieu (1992, p. 251), consiste portanto em impor, sobretudo às ciências sociais, um "novo espírito científico", de modo que as teorias se alimentem menos do confronto puramente ideológico com outras teorias e se preparem mais para o enfrentamento de novos objetos empíricos, evitando conceitos que têm por função designar, de maneira estenográfica, conjuntos de esquemas geradores de práticas científicas epistemologicamente controladas e ideologizadas.

O que o autor propõe é a elaboração, a partir do "conhecimento sobre a lógica de funcionamento dos campos de produção cultural, [de] um programa realista visando uma ação coletiva dos intelectuais" (BOURDIEU, 1992, p. 461). Esse programa deve se pautar essencialmente nas suas disposições críticas que são ao mesmo tempo o produto e a garantia de sua autonomia. É "em nome desse capital coletivo que os produtores culturais se sentem

\footnotetext{
${ }^{21}$ Bourdieu (1992, p. 293-297) apresenta uma reflexão interessante sobre "o intelectual total e a ilusão de um pensamento todo poderoso". Esse sonho, assinala Bourdieu (1992, p. 293), "se enraíza na posição social sem precedente que Sartre construiu concentrando numa única pessoa um conjunto de poderes intelectuais e sociais até então partilhados".

\begin{tabular}{l|l|l|l|l|l}
\hline (c) Rev. Inter. Educ. Sup. & Campinas, SP & v.4 & n.1 & p.95-111 & jan./abr. 2018
\end{tabular}
}


no direito e no dever de ignorar as demandas ou as exigências dos poderes temporais" (BOURDIEU, 1992, 307), pois se revestem das condições necessárias para combatê-los em nome de seus próprios princípios e normas.

É na "encarnação moderna do poder crítico dos intelectuais" que se constitui o intelectual coletivo, movido por um discurso de liberdade e de justiça social, ancorado unicamente nas orientações e controles próprios de sua posição de artista, de escritor, de sábio, armado da pluralidade de aquisições dos que os antecederam, capaz de enfrentar a oposição clássica entre o individual e o coletivo que tradicionalmente aparece como um eixo estruturante da pesquisa sociológica. Ao se referir às ameaças que pairam sobre os intelectuais, sobre sua autonomia, sobre sua exclusão cada vez maior para fora do debate público, sobre a força coercitiva do poder tecnocrático ou 'epistemocrático',22, Bourdieu (1992, p. 462) argumenta em favor do caráter coletivo da luta desse personagem ao mesmo tempo paradoxal (porque "somente pode ser pensado como tal se se apreende por meio da alternativa obrigatória da autonomia e do engajamento, da cultura pura e da política") e bidimensional (porque "investido de uma autoridade específica conferida por um mundo intelectual autônomo"). Ele vislumbra a criação de uma Internacional dos intelectuais, visando fazer sobreviver um dos últimos contrapoderes críticos capaz de se opor às forças da ordem econômica e política contemporânea.

\section{REFERÊNCIAS}

BOURDIEU, Pierre. "Il faudrait réinventer une sorte d'intellectuel collectif sur le modèle de ce qu'ont été les Encyclopédistes". Entretien concedé à Franck Nouchi. Le Monde, 1993, reprise par Courrier de l'Environnement de l'INRA. n. 22, p. 54-56. Disponível em: < http://www7.inra.fr/lecourrier/assets/C22Bourdieu.pdf>. Acesso em: 5 fev. 2017.

BOURDIEU, Pierre. A distinção. Crítica social do julgamento. São Paulo: EdUSP; Porto Alegre: ZOUK, 2007.

BOURDIEU, Pierre. Homo academicus. Florianópolis: EdUFSC, 1. ed. 2011.

BOURDIEU, Pierre. La noblesse d'État: grandes écoles et esprit de corps. Paris: Éditions de Minuit, 1989.

BOURDIEU, Pierre. Les règles de l'art. Genèse et structures du champ littéraire. Paris: Éditions du Seuil, 1992.

\footnotetext{
${ }^{22}$ Segundo Bourdieu (1992, p. 466), “os intelectuais dos diferentes países dever estar plenamente conscientes desse mecanismo se querem evitar a divisão em razão de oposições conjunturais e fenomenais que têm por princípio o fato de que a mesma vontade de emancipação se confronta com obstáculos diferentes".

\begin{tabular}{l|l|l|l|l|l} 
(C) Rev. Inter. Educ. Sup. & Campinas, SP & v.4 & n.1 & p.95-111 & jan./abr. 2018 \\
\hline
\end{tabular}
}


BOURDIEU, Pierre. O campo científico. In: ORTIZ, Renato, FERNANDES, Florestan (Org.). Pierre Bourdieu. São Paulo: Ática, 1983. p. 122-155.

BOURDIEU, Pierre. Sociologie générale. Cours au Collège de France 1981-1983. Paris: Seuil/Raisons d'Agir, 2015.

BOURDIEU, Pierre. Sur l'État. Cours au Collège de France 1989-1992. Paris: Seuil/Raisons d'Agir, 2012.

BOURDIEU, Pierre; PASSERON, Jean-Claude. Os herdeiros: os estudantes e a cultura. Florianópolis: EdUFSC, 2014.

BRUNETIÈRE, Ferdinand. Após o processo. In: DURKHEIM, Émile. O individualismo e os intelectuais. São Paulo: EdUSP, 2016. p. 135-167.

CHARLE, Christophe. Naissance des “intellectuels" (1890-1990). Paris: Éditions de Minuit, 1990.

CONSOLIM, Marcia. O século das grandes revistas parisienses: La Revue des deux mondes e a Revue bleue antes do Affaire. In: DURKHEIM, Émile. O individualismo e os intelectuais. São Paulo: EdUSP, 2016. p. 75-84.

CONSOLIM, Marcia; OLIVEIRA, Márcio de; WEISS, Raquel. Apresentação do volume. In DURKHEIM, Émile. O individualismo e os intelectuais. São Paulo: EdUSP, 2016. p. 17-33.

CORCUFF, Philippe. Figures de l'individualité, de Marx aux sociologies contemporaines. EspacesTemps.net. Travaux, 12.07.2005. Disponível em:

< http://www.espacestemps.net/articles/figures-individualite>. Acesso em: 15 mar. 2017.

DE SINGLY, François. L'individualisme est un humanisme. La Tour d'Aigues: Éditions de l'Aube, 2005.

DURKHEIM, Émile. A educação moral. Petrópolis: Vozes, 2008.

DURKHEIM, Émile. O ensino da moral na escola primária. Revista Novos Estudos CEBRAP. Edição 78, 2007, p. 59-75. Disponível em: <

http://www.scielo.br/scielo.php?script=sci_arttext\&pid=S0101-33002007000200008 >. Acesso em: 11 mar. 2017.

DURKHEIM, Émile. O individualismo e os intelectuais. São Paulo: EdUSP, 2016.

JONES, Susan Stedman. O individualismo. In: DURKHEIM, Émile. O individualismo e os intelectuais. São Paulo: EdUSP, 2016. p. 85-94.

MARTUCCELLI, Danilo; DE SINGLY, François. Les sociologies de l'individu. Paris: Armand Colin, 2. ed. 2012. 
MILLER, Willian Watts. "O individualismo e os intelectuais" de Durkheim. In:

DURKHEIM, Émile. O individualismo e os intelectuais. São Paulo: EdUSP, 2016. p. 107121.

PINTO, Louis. Durkheim, o intelectual como mandatário do universal. In: DURKHEIM, Émile. O individualismo e os intelectuais. São Paulo: EdUSP, 2016. p. 69-74.

SAPIRO, Gisèle. Modelos de intervenção política dos intelectuais: o caso francês. Revista Pós Ciências Sociais, UFMA, v. 9, n. 17, p. 19-50, 2012.

VALLE, Ione Ribeiro, CATANI, Denice Barbara, DA SILVA, Vera Lucia Gaspar, SANTOS, Tiago Ribeiro (Org.) Heranças da sociologia de Pierre Bourdieu \& Jean-Claude

Passeron. 50 anos de Os Herdeiros. Curitiba: CRV, 2015.

VALLE, Ione Ribeiro. A obra do sociólogo Pierre Bourdieu: Uma irradiação incontestável. Revista Educação e Pesquisa, São Paulo: USP, v. 33, n. 1, p. 117-134, jan./abr. 2007.

VALLE, Ione Ribeiro. Ler Homo academicus. In: BOURDIEU, Pierre. Homo academicus. Florianópolis: EdUFSC, 1. ed. 2011. p. 13-20.

VALLE, Ione Ribeiro, MEZZAROBA, Cristiano, CÂNDIDO, Helena, GRIMM, Viviane, ROHLING, Marcos (Org.). Dossiê "Pierre Bourdieu: da sociologia à educação". Revista Tempos e Espaços em Educação da Universidade Federal de Sergipe/UFS, v. 8, n. 15, 2015. Disponível em: < http://www.seer.ufs.br/index.php/revtee/issue/view/343 > Acesso em: 25 fev. 2017.

VALLE, Ione Ribeiro. O lugar da educação (escolar) na sociologia de Pierre Bourdieu.

Revista Diálogo Educacional (PUCPR. Impresso), v. 13, p. 411-437, 2013 b.

Disponível em: < http://www2.pucpr.br/reol/index.php/dialogo?dd1=7629\&dd99=view $>$.

Acesso em: 10 fev. 2017.

VALLE, Ione Ribeiro. Os herdeiros: uma das principais "teses" da sociologia francesa da educação. Revista Linhas, Florianópolis, v. 15, n. 29, p. 232-250, jul./dez. 2014.

VALLE, Ione Ribeiro. Pierre Bourdieu: A pesquisa e o pesquisador. In: BIANCHETTI, Lucídio, MEKSENAS, Paulo (Orgs.). A trama do conhecimento: Teoria, método e escrita em ciência e pesquisa. Campinas: Papirus, 2008. p. 95-117.

VIEIRA, Carlos Eduardo. Intelligentsia e intelectuais; sentidos, conceitos e possibilidades para a história intelectual. Revista Brasileira de História da Educação, Maringá, n. 16, p. 63-85, jan./abr. 2008.

WEISS, Raquel. Durkheim, um "intelectual” em defesa do "ideal humano". In: DURKHEIM, Émile. O individualismo e os intelectuais. São Paulo: EdUSP, 2016. p. 95-106.

ZOLA, Émile. J'accuse! Lettre au Président de la République. In: DURKHEIM, Émile. O individualismo e os intelectuais. São Paulo: EdUSP, 2016. p. 173. 


\section{${ }^{1}$ Sobre a autora}

\section{Ione Ribeiro Valle}

E-mail: ione.valle@ufsc.br / ORCID: http://orcid.org/0000-0001-7496-3959

Universidade Federal de Santa Catarina - Brasil

Doutorado em ciências da Educação - Université René Descartes - Paris V

Pós-doutorado na École de Hautes Études en Sciences Sociales - EHESS 